Letter to Editor

Ghulam Murtaza, PhD

Department of Neurology

College of Medicine, King Saud University

Riyadh, Saudi Arabia

Razia Sultana, MSc

Institute of Agricultural Sciences

University of the Punjab

Lahore, Pakistan

Address for correspondence:

Ghulam Murtaza

Department of Neurology

College of Medicine, King Saud University

Riyadh, Saudi Arabia

Email: gmurtazay@yahoo.com

Received, 22 January, 2017

Accepted, 9 March, 2107

$\mathrm{S}$ troke is the leading cause of death and disability globally. About one third of patients after surviving from stroke become dependent on others for care and financial support. ${ }^{14}$ There are two types of stroke, ischemic and hemorrhagic, which occur due to lack of blood flow and bleeding, respectively. The symptoms of stroke include dizziness, weakness in the arm or leg, particularly on one side of the body, dizziness, loss of balance, difficulty in seeing, speaking or understanding speech, and sudden severe headache. The risk factors for stroke include high blood pressure, diabetes, smoking, inactivity, obesity, old age, high cholesterol levels, atrial fibrillation, thrombophilia, migraine with aura, heredity, and prior stroke attack. ${ }^{8}$ In Nepal, ischaemic stroke is more prevalent than hemorrhagic stroke. Initially, smoking and alcohol consumption were considered as the main risk factors for stroke, however recent studies have indicated hypertension as the main reason for stroke. In 2012, there was 3 fold increase of hypertension in last 25 years, which was attributed to higher salt intake, urbanization, and socio-economic transition. ${ }^{12}$

Stroke is a costly disorder with respect to individual, familial and social life. In 2005 alone, about 16 million firstever stroke cases were recorded globally with 5.7 million deaths and, it is expected that there will be an increase to 23 million first-ever stroke cases and $7 \cdot 8$ million deaths by $2030 .{ }^{6}$ About $85 \%$ of all stroke deaths occur in low- and middle-income countries. In Nepal, it is one of the major diseases and causes of death. In 2006, there were about 50,000 people with stroke. Fifteen thousand people die from this disease annually. ${ }^{10}$ The long-term impairments after stroke are hugely adverse for both individual and other care sectors. Stroke patients may lose their job,
Nepal Journal of Neuroscience 14:21-22, 2017

\section{Transcranial Direct Current Stimulation Method for Stroke Management}

thus instead of supporting themselves and others, they will be depending on them. This impact can significantly be observed in low-income countries and, where joint family system prevails such as Nepal. The developed industrialised countries are spending huge money for stroke management. Previously, stroke prevalence was relatively higher in the developed countries. However, recently, it has switched to low- and middle-income countries with about $20 \%$ increase. $^{2}$

\section{Transcranial direct current stimulation (tDCS)}

It is a cheaper, non-invasive, painless, and safe method for the treatment of neurological disorders including stroke. The requirements of tDCS are a constant current stimulator and surface electrodes soaked in normal saline. The current density up to $25 \mathrm{~mA} / \mathrm{cm}^{2}$ is not harmful for brain tissue, thus application of normally used current (1-2 $\mathrm{mA} / \mathrm{cm}^{2}$ ) in tDCS falls within the safety limits. ${ }^{4}$ The anode electrode increases while cathode electrode decreases excitability, respectively. The modulation in excitability by tDCS is of clinical importance with significant improvements in outcomes of neurological impairments. ${ }^{3}$ Recent studies have revealed importance of tDCS not only in the rehabilitation of stroke patients but also in intervention on stroke risk factors. ${ }^{13}$ tDCS has advantage over other stimulation methods due to its ease of use, large size of electrodes, and its portability. Stimulation through large electrodes affects a wider region of brain including primary motor cortex, premotor, supplementary motor, and somatosensory cortices. All these regions of brain are associated with the recovery process in various diseases. ${ }^{5}$ However, certain factors may limit its application, which include its poor temporal resolution and anatomical localization. In addition, individuals' differences in hair, scalp, and bone composition can hinder current movement to the brain. ${ }^{9}$

It is well documented that risk of stroke increases with increase of age. However, in South Asian countries including Nepal, rate of young stroke incidence is higher compared to developed western countries, which is alarming condition for any country. ${ }^{7}$ In Nepal, about $2 \%$ of hospital admitted patients have stroke attack, which are expected to project if stroke remains uninterrupted. ${ }^{1}$ Rapid urbanization with low physical activities and existence of multiple risk factors such as hypertension, smoking, and alcohol consumption can further increase the risk of stroke incidence. ${ }^{10}$ It depicts greater economic burden 


\section{Murtaza et al}

on government in future. Experience of high-income countries illustrates that about $4 \%$ annual average decline in stroke mortality is achievable by intervening stroke risk factors and adopting better rehabilitation programs. ${ }^{11}$

Thus, in Nepal, introduction of tDCS being effective technique will not only improve the conditions of stroke patients but will also counter stroke risk factors. Moreover, as tDCS is inexpensive and easy to administer, its implementation will reduce the burden of stroke on Nepal government.

\section{References}

1. Bhandari GP, Angdembe MR, Dhimal M, Neupane $\mathrm{S}$, Bhusal C. State of non-communicable diseases in Nepal. Bmc Public Health 14: 2014

2. Feigin VL, Lawes CM, Bennett DA, Barker-Collo SL, Parag V. Worldwide stroke incidence and early case fatality reported in 56 population-based studies: a systematic review. Lancet Neurol 8: 355-369, 2009

3. Fregni F, Pascual-Leone A. Technology insight: noninvasive brain stimulation in neurologyperspectives on the therapeutic potential of rTMS and tDCS. Nat Clin Pract Neurol 3: 383-393, 2007

4. Mccreery DB, Agnew WF, Yuen TGH, Bullara L. Charge-Density and Charge Per Phase as Cofactors in Neural Injury Induced by Electrical-Stimulation. Ieee T Bio-Med Eng 37: 996-1001, 1990

5. Nitsche MA, Liebetanz D, Antal A, Lang N, Tergau F, Paulus W. Modulation of cortical excitability by weak direct current stimulation--technical, safety and functional aspects. Suppl Clin Neurophysiol 56: $255-276,2003$
6. Ovbiagele B, Goldstein LB, Higashida RT et al. Forecasting the future of stroke in the United States: a policy statement from the American Heart Association and American Stroke Association. Stroke 44: 2361-2375, 2013

7. Razzaq AA, Khan BA, Baig SM. Ischemic stroke in young adults of South Asia. J Pak Med Assoc 52: 417-422, 2002

8. Sacco RL, Kasner SE, Broderick JP et al. An updated definition of stroke for the 21st century: a statement for healthcare professionals from the American Heart Association/American Stroke Association. Stroke 44: 2064-2089, 2013

9. Schlaug G, Renga V, Nair D. Transcranial direct current stimulation in stroke recovery. Arch Neurol 65: 1571-1576, 2008

10. Shaik MM, Loo KW, Gan SH. Burden of stroke in Nepal. Int J Stroke 7: 517-520, 2012

11. Strong K, Mathers C, Bonita R. Preventing stroke: saving lives around the world. Lancet Neurol 6: 182-187, 2007

12. Vaidya A, Pathak RP, Pandey MR. Prevalence of hypertension in Nepalese community triples in 25 years: a repeat cross-sectional study in rural Kathmandu. Indian Heart J 64: 128-131, 2012

13. van Dun K, Bodranghien FC, Marien P, Manto MU. tDCS of the Cerebellum: Where Do We Stand in 2016? Technical Issues and Critical Review of the Literature. Front Hum Neurosci 10: 199, 2016

14. Warlow CP. Epidemiology of stroke. Lancet 352 Suppl 3: SIII1-4, 1998 